This is a pre-copyedited, author-produced version of an article accepted for publication in The Journals of Gerontology: Series A, following peer review. First published: June 7, 2020, final form available online at: https://doi.org/10.1093/gerona/glaa144

\title{
Trends of Physical Functioning, Morbidity and Disability-free Life Expectancy among the Oldest Old: Six Repeated Cross-sectional Surveys between 2001 and 2018 in the Vitality 90+ Study
}

Reference to publication:

Enroth, L., Raitanen, J., Halonen, P., Tiainen, K., \& Jylhä, M. (2020). Trends of Physical Functioning, Morbidity and Disability-free Life Expectancy among the Oldest Old: Six Repeated Cross-sectional Surveys between 2001 and 2018 in the Vitality 90+ Study. The Journals of Gerontology: Series A. https://doi.org/10.1093/gerona/glaa144 


\section{ABSTRACT}

Background: It remains unclear whether increasing longevity is accompanied by a compression or expansion of poor health and disability. We examined trends of physical functioning and morbidity in a population aged 90 and over, and disease- and disability-free life expectancy (LE) at age 90 between 2001 and 2018 in Finland's third most populated city.

Methods: We used survey data from the Vitality 90+ Study, which comprises a series of six repeated mailed surveys (7,590 observations). Information on mortality came from Statistics Finland. We examined trends of functioning (ADL and mobility) and cardiovascular and dementia morbidity using age-adjusted generalized estimating equation models stratified by sex. In addition, age, sex and period specific health expectancies were calculated using Sullivan’s method.

Results: Over time, functioning improved especially in women, and morbidity increased in men. From 2001 to 2018, LE at age 90 increased by 5.3 months for men and 6.4 months for women. LE without ADL disability increased by 5.0 months for men and 8.4 months for women, and LE without mobility disability by 6.0 months for men and 4.4 months for women. LE without cardiovascular and dementia morbidity decreased for men (2.6 months) and increased for women (1.9 months).

Conclusions: In relative terms, we found a compression of disability for both sexes and an expansion of morbidity for men. Although the trends overall are rather positive, the increase in absolute morbidity and to some extent in disability will inevitably mean increasing care needs with population aging.

Key Words: Health expectancy, time trend, oldest old 


\section{INTRODUCTION}

Declining old age mortality has brought an unprecedented increase in longevity in the 21st century, especially in high-income countries. More and more people live to a very old age, and life expectancy (LE) has reached 80 years in several countries $(1,2)$. In Finland, which has one of the world's fastest ageing populations, $12.7 \%$ of women and $3.6 \%$ of men in the 1911 birth cohort lived to 90 years of age in 2001. Just 13 years later, the figures for the 1924 birth cohort were $22.5 \%$ and $8.0 \%$ (3). In comparison to other Nordic countries and France, survival for the 1911 birth cohort was clearly lower in Finland. However, the increase in survival was faster in Finland reaching the level in Denmark in the 1924 birth cohort but was still lagging France where 30\% of women and 12\% of men reached 90 years $(3,4)$. The increase in LE is projected to continue, although the rate of that increase will depend on the assumptions used for the projections. Christensen and colleagues (2009) projected that for example in Japan, France and the US, half of all people born after the millennium will live to 100 years (2). Since chronic conditions and limitations in physical functioning are more prevalent at higher age $(5,6)$ and increasing numbers are living to old age, the question we need to ask is whether the increase in life expectancy is accompanied by an increase in healthy or disabled years.

In recent decades older people have shown improved physical functioning but an increased prevalence of chronic conditions (2,7). There is a scarcity of evidence for the fastest growing part of the population, that is, people aged 85 and over, but indications are that physical functioning is stable or slightly improving (5,8-13) and that the prevalence of chronic conditions is increasing $(8,14)$. The interplay of increasing LE with health and disability is examined by calculating health expectancies, which indicate the expected length of life lived with and without a health problem (e.g. disability or chronic conditions) at a particular age (15). Trends of health expectancies in old age are not conclusive but suggest both compression and expansion of disability (16), and only few recent studies have examined the oldest old (85+) (17-20). 
In survey studies, physical functioning is commonly assessed in terms of ability to manage activities of daily living (ADL), which not only reflects individuals' quality of life but also has repercussions at the level of society as a whole. The rapid growth of the oldest old population has raised concerns over the challenges faced in the provision of adequate care and assistance since limitations in ADL often imply a constant need for help from another person.

The evidence on time trends in physical functioning, chronic conditions and health expectancies in the oldest old population is still fragmented. Only few studies have included institutionalized individuals in their analyses of oldest old populations or involved more than two repeated measurement points. Yet it is widely recognized that we need to monitor trends and inequality in health and functioning. One potentially useful indicator for this purpose is disability-free life expectancy (DFLE) (21). Our aim in this study was to identify patterns of physical functioning, morbidity and health expectancies in nonagenarians and, secondly, to assess whether these patterns show compression, stability or expansion between 2001 and 2018. Using population based data with high response rates and the exact same methods, we examined trends of physical functioning and morbidity for six cohorts born between 1911 and 1928 and explored the length of time lived without disability and diseases at age 90. As women live longer than men and have higher disability rates, $(22,23)$ all analyses were stratified by sex. 


\section{METHODS}

\section{Study participants}

We used survey data from the Vitality 90+ Study. The Vitality 90+ Study is based on surveys in the population aged 90 and over in Finland's third largest city (12). Data were collected six times (2001, 2003, 2007, 2010, 2014, and 2018) with the same questions. Since all individuals aged 90 and over were contacted in each study year, multiple participation was possible. The total number of participants was 5,540 and there were 7,590 observations. The response rates varied between $76.7 \%$ and $86.3 \%$.

Individuals in round-the-clock care and proxy respondents were included in the study in order to generate findings representative of the total population. The round-the-clock care refers to living in a nursing home or service housing with round-the-clock assistance. Responses were considered proxyreported if they were given by a family member, friend or a staff member at home help or nursing home; and independent if they were given by the participant alone or with practical help of a family member, friend or a staff member at home.

The study protocol was approved by the Ethics Committee of the City of Tampere and for more recent study waves the Regional Ethics Committee of Tampere University Hospital. All participants or their legal representatives gave written informed consent.

\section{Measures of functioning and morbidity}

Physical functioning was assessed with five activities: ability to climb stairs, to walk 400 metres, and to move indoors (mobility); and ability to get in and out of bed and to dress and undress (ADL). The response options to the question "Are you able to ...” were 1) Yes, without difficulty, 2) Yes, with difficulty, 3) Only with help, and 4) Not at all. Respondents were considered independent in mobility if they chose response options 1 or 2 in all three activities; and independent in ADL if they chose options 1 or 2 in both activities. Similar self-reported ADL and mobility indicators have been shown to correlate with physical performance tests in the oldest old population (24). 
The participants were asked whether they had particular doctor diagnosed diseases (yes/no). Out of eight available diseases or conditions, we examined three cardiovascular diseases namely heart disease, stroke and diabetes, and additionally dementia (dementias, Alzheimer's disease, or decline in cognition). High age is one of the main risk factors for these four potentially disabling diseases that increase care needs. Diseases of circulatory system represent more than $40 \%$ and dementias and Alzheimer's diseases almost $40 \%$ of the main causes of death among the oldest old (25). Our binary measure of cardiovascular and dementia morbidity was categorized as either being free of all four diseases or having at least one of the four diseases.

\section{Health expectancy}

We determined disability-free and disease-free LEs based on the prevalence of independence in mobility and ADL, and being free of four diseases. Period life tables were constructed using data from Statistics Finland. They were based on the person years lived in each age group and the number of deaths in the age group.

\section{Statistical analysis}

We tested differences in population characteristics between study years with Chi-squared test. To examine trends in physical functioning and morbidity, analyses were conducted with generalized estimating equations (GEE) which take into account correlation between observations for individuals who participated in more than one data collection (26). Binomial outcomes were analyzed with logit link. Analyses were adjusted for age and stratified by sex. To examine whether level of functioning and morbidity changed over time (2001-2018), a linear trend was tested using the contrast command. Health expectancies were calculated with Sullivan's method $(15,27)$. Calculations were conducted using an unabridged life table (single years of age), which was closed at the age of 100 . Confidence intervals were calculated for health expectancies to assess differences between study years. The analyses were run with statistical software Stata version 14 and statistical significance was set at p < 0.05 . 


\section{RESULTS}

As expected, most of the oldest old participants were women, but the proportion of men increased from $19.3 \%$ in 2001 to $26.1 \%$ in 2018 (p-value <0.001). Over the study period the median age remained at 92 for women and varied between 91 and 92 for men. The proportion of women in roundthe-clock care decreased from $43.2 \%$ to $32.0 \%$ (p-value $<0.001$ ) and fluctuated between $21.6 \%$ and $32.1 \%$ among men (p-value 0.03 ). The proportion of proxy respondents was between $20.7 \%$ and 25.3\% among women and between 13.7\% and 15.3\% among men in 2001, 2003, 2010, 2014 but somewhat lower in 2007 (women 16.9\% and men 8.3\%) and 2018 (women 17.2\% and men 10.5\%) (p-value $<0.001$ for women) (Table 1$)$.

For women, we found improvement in ADL, mobility and in all five individual activities from 2001 to 2018. The odds of being independent in ADL and especially in mobility activities were clearly higher only in the last study years. Thus, the significant linear trend that we found for all activities was largely driven by the improvement in functioning in the last study years. For men, no significant trends were found in either individual or the summarized measures of ADL and mobility, but ability to move indoors was higher in 2018 than in 2001. Among women, the prevalence of morbidity (being free of heart disease, stroke, diabetes, and dementia) remained stable over the study period. For men, the odds of being free of diseases decreased, especially from 2010 onwards, showing a significant linear trend over time. Their higher morbidity was mainly due to an increase in heart diseases and diabetes (Table 2; Figure 1; eFigure 1).

Total LE at age 90 increased gradually from 3.37 to 3.81 years (5.3 months) for men and from 3.90 to 4.43 years (6.4 months) for women from 2001 to 2018 (Figure 2; Figure 3). LE without ADL disability increased, with some fluctuation, from 2.69 to 3.11 years (5.0 months) for men and from 2.70 to 3.40 years (8.4 months) for women. Based on the calculated confidence intervals, LE without ADL disability was significantly higher in the later study years for both sexes (eTable 1). LE with ADL disability varied only slightly over time, increasing by 0.2 months for men and decreasing by 
2.0 months for women. DFLE as a proportion of total LE increased from $69.1 \%$ to $76.8 \%$ for women and fluctuated between $79.8 \%$ and $84.6 \%$ for men.

LE without mobility disability increased gradually from 1.90 to 2.40 years (6.0 months) for men and from 1.47 to 1.84 (4.4 months) for women over time, with only exception of 2010 (Figure 2; Figure 3). LE without mobility disability was higher for men than for women in each study year (eTable 1). LE with mobility disability decreased for men by 0.7 months and increased for women by 1.9 months. DFLE as a proportion of LE fluctuated between $56.3 \%$ and $63.0 \%$ among men and $35.2 \%$ and $41.5 \%$ among women over time but was somewhat higher in later study years. LE free of cardiovascular and dementia morbidity decreased, with some fluctuation, from 1.06 to 0.84 years (2.6 months) for men and increased from 0.86 to 1.02 years (1.9 months) for women. Consequently, LE with at least one disease increased by 7.9 months for men and 4.4 months for women. Disease-free LE as a proportion of LE decreased from $31.4 \%$ to $21.9 \%$ for men and reached the morbidity level that for women was stable throughout the study years. 


\section{DISCUSSION}

The beginning of the 21st century saw a rapid increase in Finland's oldest old population. From 2001 to 2018, LE at age 90 increased by around six months. This study set out to examine the level of physical functioning and cardiovascular and dementia morbidity in six cohorts born between 1911 and 1928 and to assess whether the rise in LE was accompanied by an increase in disability-free or disabled months. Our findings show that women's functioning (ADL and mobility) and DFLE improved over time. The findings for men show greater variation between study years but suggest some improvement in DFLE regarding mobility, for instance. We also examined morbidity from cardiovascular diseases and dementia, which are known drivers for disability, and found no change for women over time. For men, morbidity increased by around 10 percentage points and reached women’s morbidity level.

DFLE is a measure that combines length of life and level of disability. Interpretation of DFLE trends are often based on hypotheses about the compression or expansion of morbidity. The compression of morbidity, defined as a greater postponement of the onset of morbidity than the increase in LE, would lead to a shorter period of life with morbidities (28). In this study where ADL and mobility were used as disability indicators, DFLE as a proportion of total LE increased for both sexes, suggesting compression of disability. The expansion of morbidity (or failure of success, as it is also called) refers to an increase in years lived with morbidity, as the age at onset of morbidity remains the same while LE increases (29). We found expansion of morbidity for men, with an increase in the proportion of LE lived with at least one disease and an increase in the length of the diseased period. For women, the proportion of LE lived with at least one disease remained constant between 2001 and 2018, but the length of the diseased period increased.

It is difficult to directly compare our findings with earlier studies because of differences in indicators of ADL, mobility and morbidity, differences in survey methods used, time periods, country, etc. (7). However, in line with Christensen et al. (2013) and Zeng et al. (2017) who reported findings for 
nonagenarians, we found better ADL functioning in later study years for women, but our results did not show as evident an improvement for men. When we compare the current findings with our earlier analyses using the same data but covering a shorter period (2001-2010) (12,30), which showed no change in the prevalence of disability for men or for women, it is noteworthy that the slight improvement observed in functioning is a very recent development. Earlier studies among older people aged 85 years $(17,18)$ have shown, as do our results here, an increase in LE without severe disability (comparable to our ADL indicator). However, for milder disability, the trends for men and women show variation between the studies.

In line with Hung et al. (2011), we found an increase in the prevalence of having at least one chronic condition (including heart disease, diabetes and stroke) but only for men. In this study, the increase in morbidity for men was driven by the increase in diabetes and to some extent in heart diseases while the prevalence for dementia and stroke remained constant. There was also increase in diabetes for women, but it was compensated with a minor decline in other conditions. Our study coincides well with earlier findings suggesting increase in diabetes for later born cohorts but partly contradicts with the findings suggesting decline in cardiovascular diseases and dementia (31). There is evidence of improved cognition also for the oldest old (11) but not in all studies (5). This study was limited to four diseases, which are important for disease burden in this age group, are associated with functional disability, need for care and are the most common causes of death in the oldest old population. However, this means that in our case being disease-free does not mean being free of all possible diseases but specifically, not having heart disease, stroke, diabetes or dementia.

In 2001, LE was higher for women than for men and it also increased more for women in the following 17 years. Thus, sex differences in LE at age 90 increased during the study period. Being free of ADL and mobility disability as a proportion of LE was higher for men than women. Also the proportion of LE free of morbidity was higher for men until 2010, but after that there was no difference between men and women. Longitudinal studies using multistate modelling $(22,23,32)$ have also shown longer 
LE and shorter DFLE among the oldest old women. Sex differences in functioning and mortality arise from diverse biological, contextual and behavioral factors. Women have more disabling diseases such as arthritis and men more lethal diseases including heart diseases, stroke and diabetes, which partly explains the longer but more morbid lives of women (33).

In addition to analysis for the total $90+$ population, we run sensitivity analysis for those aged 90-91 years old to examine only those who participated in the study for the first time. Similarly to the analysis of total $90+$ population, we found increase in ability to perform ADLs for women and increase in morbidity for men. It is reasonable to believe that the later birth cohorts in this study (who were born between 1911 and 1928) have benefitted from better living conditions (housing and education), advances in medical care (vaccinations, treatments, and rehabilitation) and healthier lifestyles (11). In the Finnish case it is particularly noteworthy that, the country suffered a civil war in 1918 and saw the introduction of compulsory education in the 1920s. Developments in the surrounding society that have contributed to increasing longevity and improving ADL functioning may also contribute to explain the expansion of morbidity. The dynamics driving this trend are related to 1) the incidence of a health condition and 2) survival among people with and without the condition (34). The expansion of morbidity may arise from improved disease control (early diagnosis and active treatments), which increases the prevalence of morbidity. However, if better disease control makes diseases less lethal, morbidity expansion also occurs as a result of increasing survival rates among people with morbidities. There is evidence of decline in mortality from cardiovascular diseases (35) and dementias (36), especially for younger old age groups.

We attempted to assess whether the selection of the study samples differed over the 17-year study period of our research and whether the changes in the percentage of proxy responses had any effect on our findings. The selection of the study samples was assessed by examining individual-based short-term mortality, which was derived from the Population Register and was linked with survey data using personal identification number. In the first 120 days after data collection, mortality was 
higher for those who did not participate in the study compared to those who did. Thus, it is likely that our study represents the healthier end of the population, as tends to be the case in survey studies (37). Short-term mortality was from 3.4 to 3.9 times higher for non-respondents than for respondents between 2010 and 2018 and somewhat higher in earlier study years, indicating that there is no reason to believe that the population was more selected in 2018. The percentage of proxy responses varied over time, and the proportion of family members serving as a proxy increased and that of staff in round-the-clock care decreased. This was probably due to the overall decrease in the number of people in round-the-clock care (39\% in 2001 and 30\% in 2018). In general, functioning was poorer for those with a proxy respondent than for those who answered themselves. Over time, we found that women with a proxy respondent showed some tendency towards improved functioning. Overall, proxies tend to rate the disability of older people higher than older people themselves, but the two types of proxies, family member and staff in institution, have been shown to have high agreement in their assessments of functioning (38). It seems unlike, then, that our findings are driven by changes in the proportion of proxy respondents.

The unique dataset used in this study is based on large well-defined cohorts of the oldest old, including people living in round-the-clock care. The demographic changes in the city of Tampere are well comparable with the changes in Finland between 2001 and 2018 with respect to doubling in the 90+ population, increase in the relative proportion of $90+$ population (from $0.5 \%$ to $0.9 \%$ ) and increase in the proportion of men in this age group (4-5\%). The study period was long (17 years) and the data for all six study waves were collected with a similar survey design under the supervision of the same person (MJ). For the data used in this study, the exact same questions were asked in each questionnaire, with the same response options. The response rates were very high (76.7\%-86.0\%). We also had access to mortality information for those who did not participate in the study, which made it possible to assess study selection. With regard to the limitations of the study, the information for our three health and functioning indicators was based on self-reports, which makes our findings 
prone to changes in living conditions and level of cognition, for instance (11). However, the prevalence of those who reported having dementia was stable throughout the study. The methodological constrains related to the use of Sullivan's method include the assumption of similar mortality for disabled and nondisabled individuals. Furthermore, it is impossible to take into account recovery from disability or morbidity (34). The latter constrain is less important in the oldest old population since recovery from disability and chronic conditions in not very common.

Our findings show that functioning, measured in terms of activities of daily living and mobility, improved from 2001 to 2018 among individuals aged 90 years and over, and that women showed more improvement than men. We also found evidence of compression of disability for both sexes, which means a shorter period of LE spent with disability in later study years. In addition, our results indicate an expansion of cardiovascular and dementia morbidity for men. Despite the rather positive trends in functioning and disability-free life expectancy between 2001 and 2018, this improvement does not directly translate into less need for care. At a population level, functioning did not improve enough to offset the doubling of the $90+$ population, since the absolute number of disabled years did not decrease. Based on the calculated health expectancies for exact 90 years old in the city of Tampere, ADL and mobility disability and morbidity increased by 171, 523 and 869 person-years, respectively. Extrapolating our findings to the Finnish population aged 90 and over, the number of individuals who need help in ADLs increased by 40\% (from 6,700 to 11,200), those who need help in mobility by $50 \%$ (from 13,680 to 27,130 ) and individuals with morbidity by $55 \%$ (from 18,180 to 39,960) between 2001 and 2018. Worldwide, the projection that there will be more than 21 million people aged 90 and over in 2020 (39) highlights the magnitude of the increase in care needs. Living longer with complex but non-fatal health problems is resource-draining and puts health care systems and families under considerable pressure. Given the continuing growth of the oldest old population, it is essential that the health and functioning of future cohorts are closely followed in order to provide a sound and sustainable basis for planning health and social care services. 


\section{Funding}

The work was supported by the NordForsk project Social Inequalities in Ageing (74637); and the Academy of Finland Centre of Excellence in Research on Ageing and Care (312311).

\section{Conflict of interest}

The authors declare no conflicts of interest.

\section{Acknowledgments}

We wish to thank the study participants and their families, the city of Tampere and the municipal and private home care, round-the-clock long-term care and hospitals in Tampere for contributing to the study. All authors of the study, LE, JR, PH, KT and MJ, contributed to the study design and drafting the paper. LE, JR and MJ designed the analyses, and LE and JR conducted the analyses. LE wrote the first draft and all authors edited the paper. 


\section{REFERENCES}

1. Crimmins EM. Lifespan and healthspan: past, present, and promise. Gerontologist. 2015;55:901-911. https://doi.org/10.1093/geront/gnv130

2. Christensen K, Doblhammer G, Rau R, Vaupel JW. Ageing populations: the challenges ahead. Lancet. 2009;374:1196-1208. https://doi.org/10.1016/S0140-6736(09)61460-4

3. Human Mortality Database. University of California, Berkeley (USA), and Max Planck Institute for Demographic Research (Germany). 2017; Available at: www.mortality.org. Accessed March 30, 2020

4. Jørgensen TSH, Fors S, Nilsson CJ, et al. Ageing populations in the Nordic countries: mortality and longevity from 1990 to 2014. Scand J Public Health. 2018;47:611-617. https://doi.org/10.1177/1403494818780024

5. Zeng Y, Feng Q, Hesketh T, Christensen K, Vaupel JW. Survival, disabilities in activities of daily living, and physical and cognitive functioning among the oldest-old in China: a cohort study. Lancet. 2017;389:1619-1629. https://doi.org/10.1016/S0140-6736(17)30548-2

6. Liu Z, Han L, Wang X, Feng Q, Gill TM. Disability prior to death among the oldest-old in China. J Gerontol A Biol Sci Med Sci. 2018;73:1701-1707. https://doi.org/10.1093/gerona/gly010

7. Chatterji S, Byles J, Cutler D, Seeman T, Verdes E. Health, functioning, and disability in older adults_-present status and future implications. Lancet. 2015;385:563-575.

https://doi.org/10.1016/S0140-6736(14)61462-8

8. Hung WW, Ross JS, Boockvar KS, Siu AL. Recent trends in chronic disease, impairment and disability among older adults in the United States. BMC Geriatr. 2011;11:47. https://doi.org/10.1186/1471-2318-11-47

9. Angleman SB, Santoni G, Von Strauss E, Fratiglioni L. Temporal trends of functional dependence and survival among older adults from 1991 to 2010 in Sweden: Toward a healthier aging. J Gerontol A Biol Sci Med Sci. 2015;70:746-752. https://doi.org/10.1093/gerona/glu206 
10. Rasmussen SH, Thinggaard M, Højgaard MB, Jeune B, Christensen K, Andersen-Ranberg K. Improvement in activities of daily living among Danish centenarians?-A comparative study of two centenarian cohorts born 20 years apart. J Gerontol A Biol Sci Med Sci. 2017;73:1125-1131. https://doi.org/10.1093/gerona/glx113

11. Christensen K, Thinggaard M, Oksuzyan A, et al. Physical and cognitive functioning of people older than 90 years: a comparison of two Danish cohorts born 10 years apart. Lancet. 2013;382:1507-1513. https://doi.org/10.1016/S0140-6736(13)60777-1

12. Jylhä M, Enroth L, Luukkaala T. Trends of functioning and health in nonagenarians: The Vitality 90 study. Annu Rev Gerontol Geriatr. 2013;33:313-332.

13. Santoni G, Angleman SB, Ek S, et al. Temporal trends in impairments of physical function among older adults during 2001-16 in Sweden: towards a healthier ageing. Age Ageing. 2018;47:698-704. https://doi.org/10.1093/ageing/afy085

14. Pefoyo AJK, Bronskill SE, Gruneir A, et al. The increasing burden and complexity of multimorbidity. BMC Public Health. 2015;15:415. https://doi.org/10.1186/s12889-015-1733-2 15. Jagger C, Van Oyen H, Robine J. Health expectancy calculation by the Sullivan method: a practical guide. Nihon University Population Research Institute (NUPRI) Research Paper Series $2014 ; 68$.

16. Jagger C, Robine J. Healthy life expectancy. In: International handbook of adult mortality. Springer, 2011:551-68.

17. Crimmins EM, Zhang Y, Saito Y. Trends over 4 decades in disability-free life expectancy in the United States. Am J Public Health. 2016;106:1287-1293.

https://doi.org/10.2105/AJPH.2016.303120

18. Jagger C, Matthews FE, Wohland P, et al. A comparison of health expectancies over two decades in England: results of the Cognitive Function and Ageing Study I and II. Lancet. 2016;387:779-786. https://doi.org/10.1016/S0140-6736(15)00947-2 
19. Liu Z, Han L, Feng Q, et al. Are China’s oldest-old living longer with less disability? A longitudinal modeling analysis of birth cohorts born 10 years apart. BMC Med. 2019;17:23. https://doi.org/10.1186/s12916-019-1259-z

20. Yong V, Saito Y, Chan A. Changes in the prevalence of mobility limitations and mobile life expectancy of older adults in Singapore, 1995-2005. J Aging Health. 2010;22:120-140. https://doi.org/10.1177/0898264309351932

21. Marmot M, Goldblatt P. Importance of monitoring health inequalities. BMJ. 2013;347:f6576. doi: https://doi.org/10.1136/bmj.f6576

22. Kingston A, Davies K, Collerton J, et al. The contribution of diseases to the male-female disability-survival paradox in the very old: results from the Newcastle 85 study. PloS one. 2014;9:e88016. https://doi.org/10.1371/journal.pone.0088016

23. Hoogendijk EO, van der Noordt M, Onwuteaka-Philipsen BD, et al. Sex differences in healthy life expectancy among nonagenarians: A multistate survival model using data from the Vitality 90 study. Exp Gerontol. 2019;116:80-85. https://doi.org/10.1016/j.exger.2018.12.015

24. Bravell ME, Zarit SH, Johansson B. Self-reported activities of daily living and performancebased functional ability: a study of congruence among the oldest old. Eur J Ageing. 2011;8:199209. https://doi.org/10.1007/s10433-011-0192-6

25. Official Statistics of Finland (OSF): Causes of death [e-publication]. Causes of death in 2018. Helsinki: Statistics Finland [referred: 24.3.2020]. http://www.stat.fi/til/ksyyt/2018/ksyyt_2018_2019-12-16_kat_001_en.html 26. Raitanen J, Stenholm S, Tiainen K, Jylhä M, Nevalainen J. Longitudinal change in physical functioning and dropout due to death among the oldest old: a comparison of three methods of analysis. Eur J Ageing. 2019. https://doi.org/10.1007/s10433-019-00533-x

27. Sullivan DF. A single index of mortality and morbidity. HSMHA Health Rep. 1971;86:347. 
28. Fries JF. Aging, natural death, and the compression of morbidity. Bull World Health Organ. 2002;80:245-250.

29. Gruenberg EM. The failures of success. The Milbank Memorial Fund Quarterly. Health and Society. 1977;3-24. DOI: 10.2307/3349592

30. Sarkeala T, Nummi T, Vuorisalmi M, Hervonen A, Jylhä M. Disability trends among nonagenarians in 2001-2007: Vitality 90+ Study. Eur J Ageing. 2011;8:87-94.

https://doi.org/10.1007/s10433-011-0188-2

31. Derby CA, Katz MJ, Lipton RB, Hall CB. Trends in dementia incidence in a birth cohort analysis of the Einstein Aging Study. JAMA Neurol. 2017;74:1345-1351. doi:10.1001/jamaneurol.2017.1964

32. Pérès K, Jagger C, Lièvre A, Barberger-Gateau P. Disability-free life expectancy of older French people: Gender and education differentials from the PAQUID cohort. Eur J Ageing. 2005;2:225-233. https://doi.org/10.1007/s10433-005-0006-9

33. Crimmins EM, Shim H, Zhang YS, Kim JK. Differences between men and women in mortality and the health dimensions of the morbidity process. Clin. Chem. 2019;6:135-145. https://doi.org/10.1373/clinchem.2018.288332

34. Crimmins EM, Hayward MD, Hagedorn A, Saito Y, Brouard N. Change in disability-free life expectancy for Americans 70 years old and older. Demography. 2009;46:627-646. https://doi.org/10.1353/dem.0.0070

35. Sidney S, Quesenberry CP, Jaffe M, et al. Recent trends in cardiovascular mortality in the United States and public health goals. JAMA Cardiol. 2016;1:594-599. doi:10.1001/jamacardio.2016.1326

36. van de Vorst IE, Vaartje I, Bots ML, Koek HL. Decline in mortality in patients with dementia: Results from a nationwide cohort of 44258 patients in the Netherlands during 2000 to 2008. Int J Geriatr Psychiatry. 2018;33:1620-1626. https://doi.org/10.1002/gps.4960 
37. Wagner M, Kuppler M, Rietz C, Kaspar R. Non-response in surveys of very old people. Eur J Ageing. 2019;16:249-258. https://doi.org/10.1007/s10433-018-0488-X

38. Lum TY, Lin W, Kane RL. Use of proxy respondents and accuracy of minimum data set assessments of activities of daily living. J Gerontol A Biol Sci Med Sci. 2005;60:654-659.

https://doi.org/10.1093/gerona/60.5.654

39. United Nations, Department of Economic and Social Affairs, Population Division. World Population Prospects 2019, Online Edition. 
Table 1. Characteristics of participants and observed prevalences of functioning and morbidity by sex in the Vitality 90+ Study 2001-2018.

\begin{tabular}{|c|c|c|c|c|c|c|c|c|c|c|c|c|}
\hline Study year & \multicolumn{2}{|c|}{2001} & \multicolumn{2}{|c|}{2003} & \multicolumn{2}{|c|}{2007} & \multicolumn{2}{|c|}{2010} & \multicolumn{2}{|c|}{2014} & \multicolumn{2}{|c|}{2018} \\
\hline Response rate \% & \multicolumn{2}{|c|}{79.0} & \multicolumn{2}{|c|}{86.3} & \multicolumn{2}{|c|}{82.3} & \multicolumn{2}{|c|}{79.5} & \multicolumn{2}{|c|}{79.6} & \multicolumn{2}{|c|}{76.7} \\
\hline Study participants $\mathbf{N}$ & \multicolumn{2}{|c|}{892} & \multicolumn{2}{|c|}{961} & \multicolumn{2}{|c|}{944} & \multicolumn{2}{|c|}{1277} & \multicolumn{2}{|c|}{1637} & \multicolumn{2}{|c|}{1879} \\
\hline Sex & Men & Women & Men & Women & Men & Women & Men & Women & Men & Women & Men & Women \\
\hline $\mathrm{N}$ & 172 & 720 & 190 & 771 & 193 & 751 & 240 & 1037 & 378 & 1259 & 491 & 1388 \\
\hline \multicolumn{13}{|l|}{ Age } \\
\hline Median & 91 & 92 & 91 & 92 & 91 & 92 & 91.5 & 92 & 92 & 92 & 91 & 92 \\
\hline Range & $90-102$ & $90-106$ & $90-102$ & $90-106$ & $90-99$ & $90-105$ & $90-99$ & $90-107$ & $90-103$ & $90-106$ & $90-107$ & $90-105$ \\
\hline \multicolumn{13}{|l|}{ Place of stay \% } \\
\hline Home & 78.4 & 56.8 & 76.8 & 61.1 & 77.7 & 62.7 & 67.9 & 61.4 & 70.7 & 62.9 & 76.4 & 68.0 \\
\hline Institutional long-term care & 21.6 & 43.2 & 23.2 & 38.9 & 22.3 & 37.3 & 32.1 & 38.6 & 29.3 & 37.1 & 23.6 & 32.0 \\
\hline \multicolumn{13}{|l|}{ Respondent \% } \\
\hline Participant & 84.7 & 74.7 & 86.3 & 76.5 & 91.7 & 83.1 & 84.9 & 76.4 & 85.4 & 79.3 & 89.6 & 82.8 \\
\hline Proxy & 15.3 & 25.3 & 13.7 & 23.5 & 8.3 & 16.9 & 15.1 & 23.6 & 14.6 & 20.7 & 10.5 & 17.2 \\
\hline
\end{tabular}




\section{Functioning \%}

\section{Independent in activity}

Climb stairs

Walk 400m

Move indoors

Get in and out of bed

$\begin{array}{llll}66.1 & 46.6 & 71.7 & 46.5\end{array}$

$66.1 \quad 46.3$

69.7

46.5

$67.4 \quad 47.4$

69.4

45.8

65.0

47.4

70.1

Dress and undress

88.4

78.4

$90.4 \quad 81.5$

69.3

49.9

68.1

47.5

68.8

50.5

72.5

52.9

$\begin{array}{llll}89.5 & 78.6 & 91.5 & 80.0\end{array}$

$82.5 \quad 88.5$

$81.2 \quad 89.6$

82.0

93.3

85.4

$80.2 \quad 69.9$

$83.5 \quad 72.7$

92.2

82.4

91.2

81.4

89.1

82.0

92.5

85.6

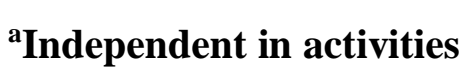

Mobility

57.3

39.2

62.6

38.1

59.9

38.3

60.4

36.2

59.5

63.3

42.0

Activities of daily living

80.2

69.9

83.5

72.0

83.4

74.5

84.9

73.7

82.4

73.4

82.7

76.8

${ }^{b}$ Morbidity \%

Free of diseases

31.8

22

37.0

23.1

25.3

20.3

21.6

23.0

22.0

22.4

21.1

23.0

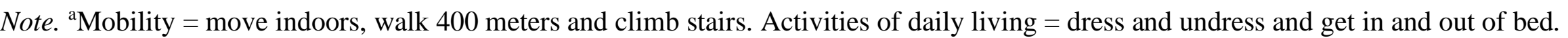

${ }^{\mathrm{b}}$ Being free of diseases refers to not having heart disease, stroke, diabetes or dementia. 
Table 2. Age-adjusted physical functioning (individual and summarized activities) and morbidity by sex in the Vitality 90+ Study $2001-2018$.

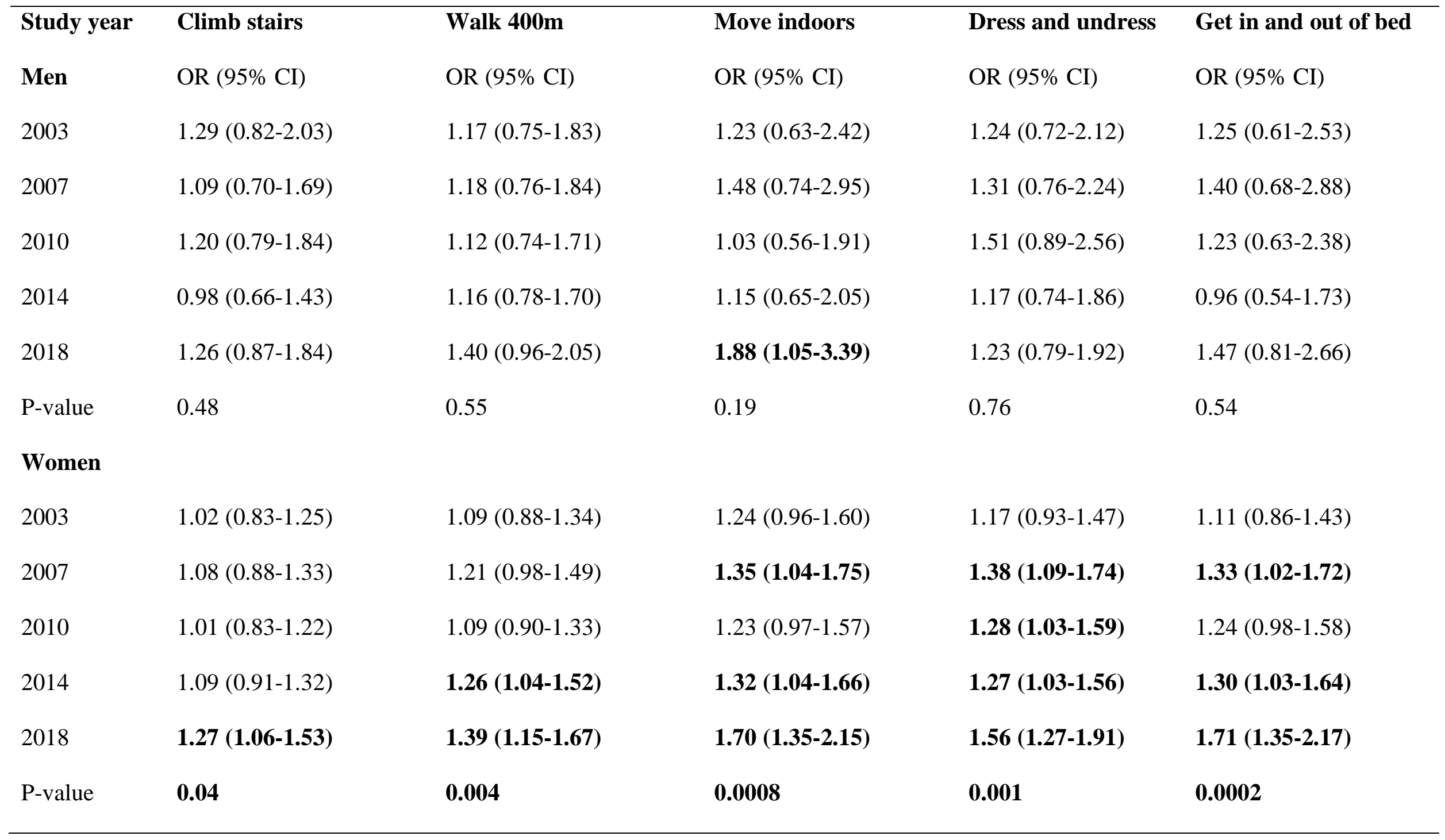




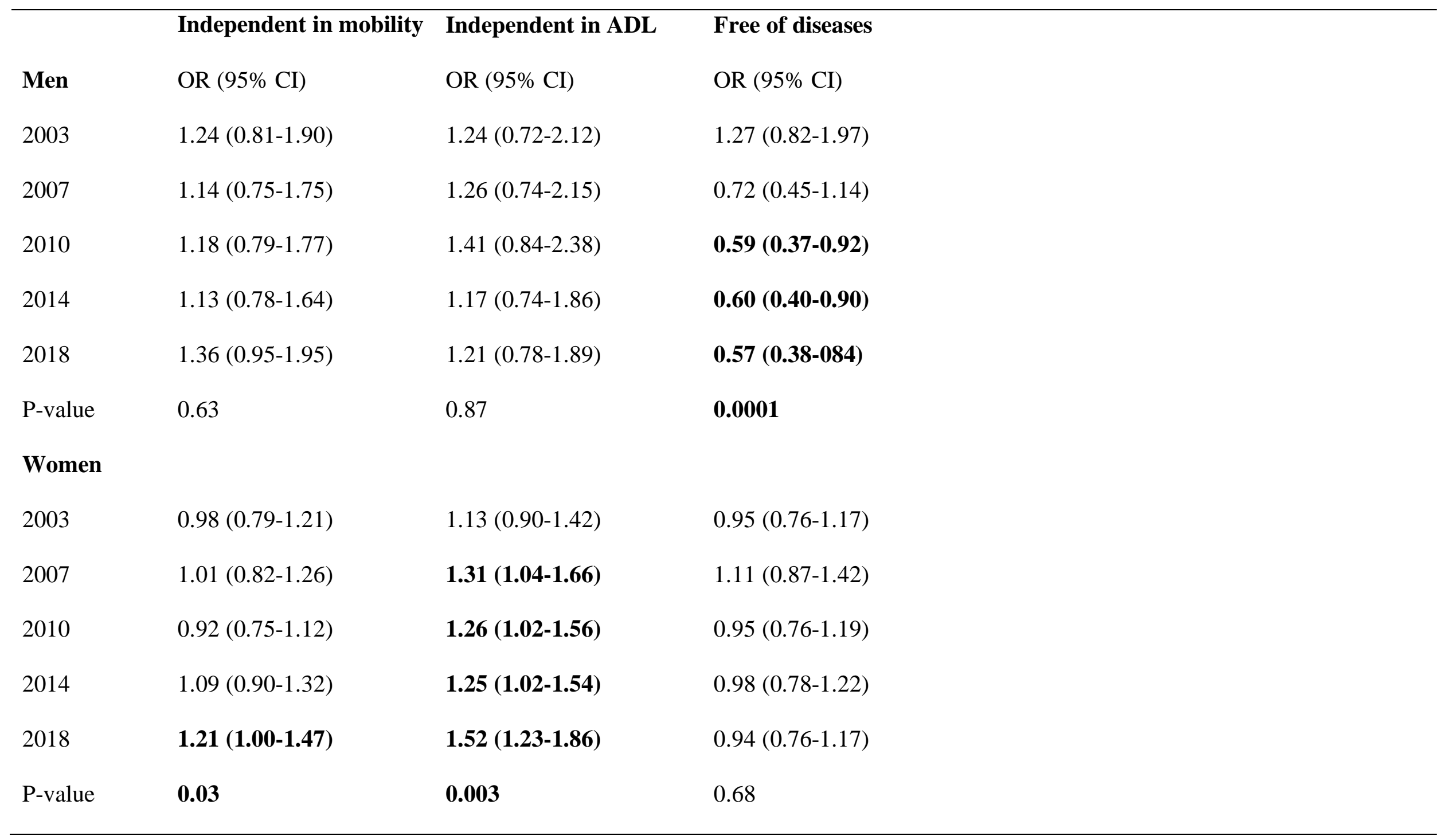


Note. Odds ratios (OR) with 95\% confidence intervals (CI) are from generalized estimating equations analysis. P-value is for a linear trend. The reference year is 2001. Statistically significant $(\mathrm{p}<.05)$ results are bolded 


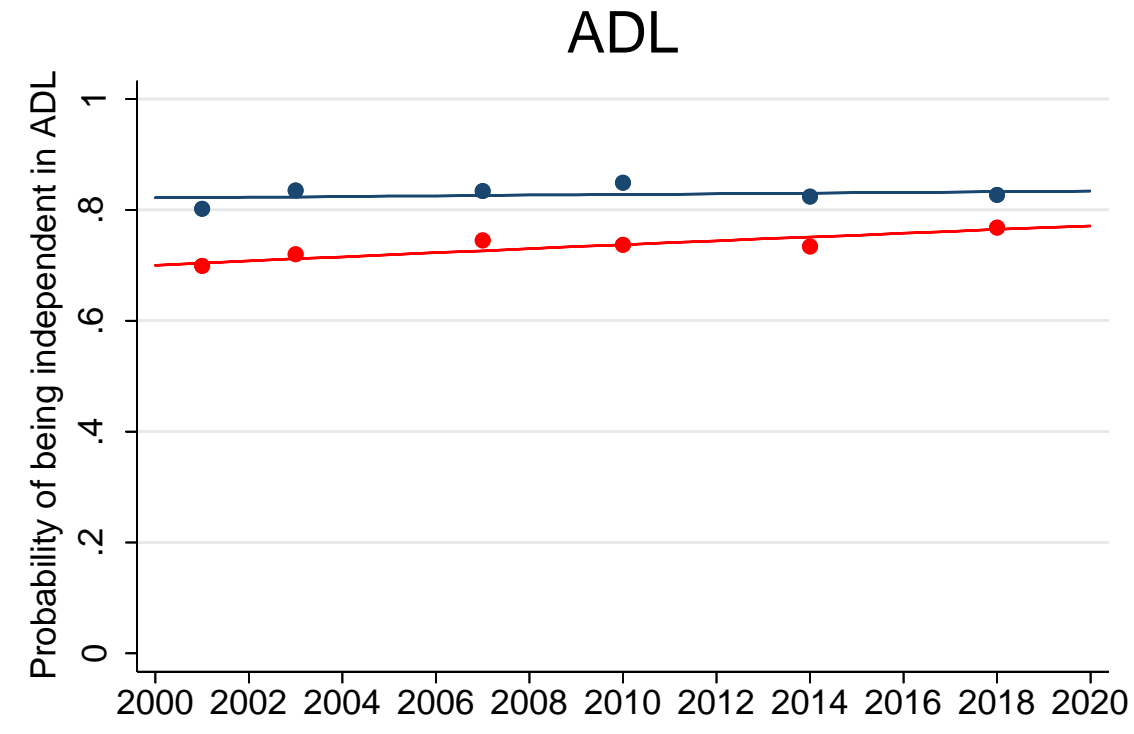

Year

\section{Morbidity}

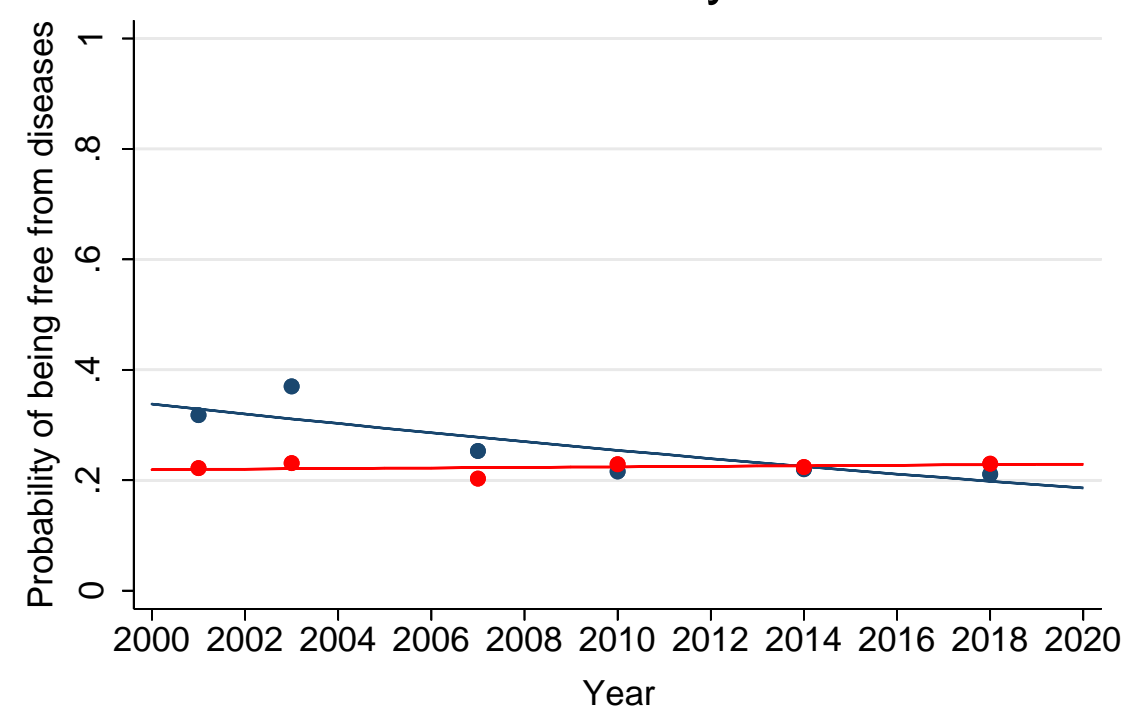

Mobility

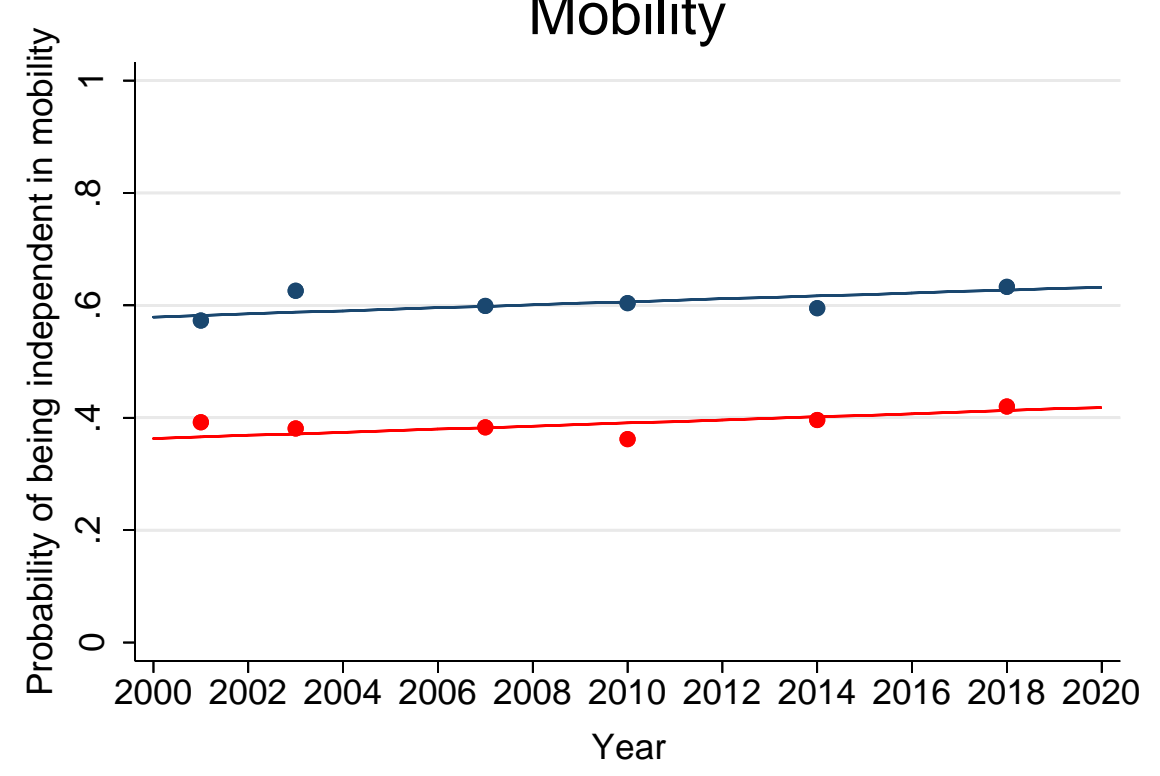

\begin{tabular}{|lll|}
\hline & Men (fitted) & $\bullet$ Men (observed) \\
$-\quad$ Women (fitted) & $\bullet$ & Women (observed) \\
\hline
\end{tabular}


Figure 1. Trends in ability to perform activities of daily living (ADL) and mobility activities and trend of being free of morbidity by sex in the Vitality $90+$ Study between 2001 and 2018.

Note. Observed probabilities and age-adjusted fitted trajectories are from generalized estimating equations. 


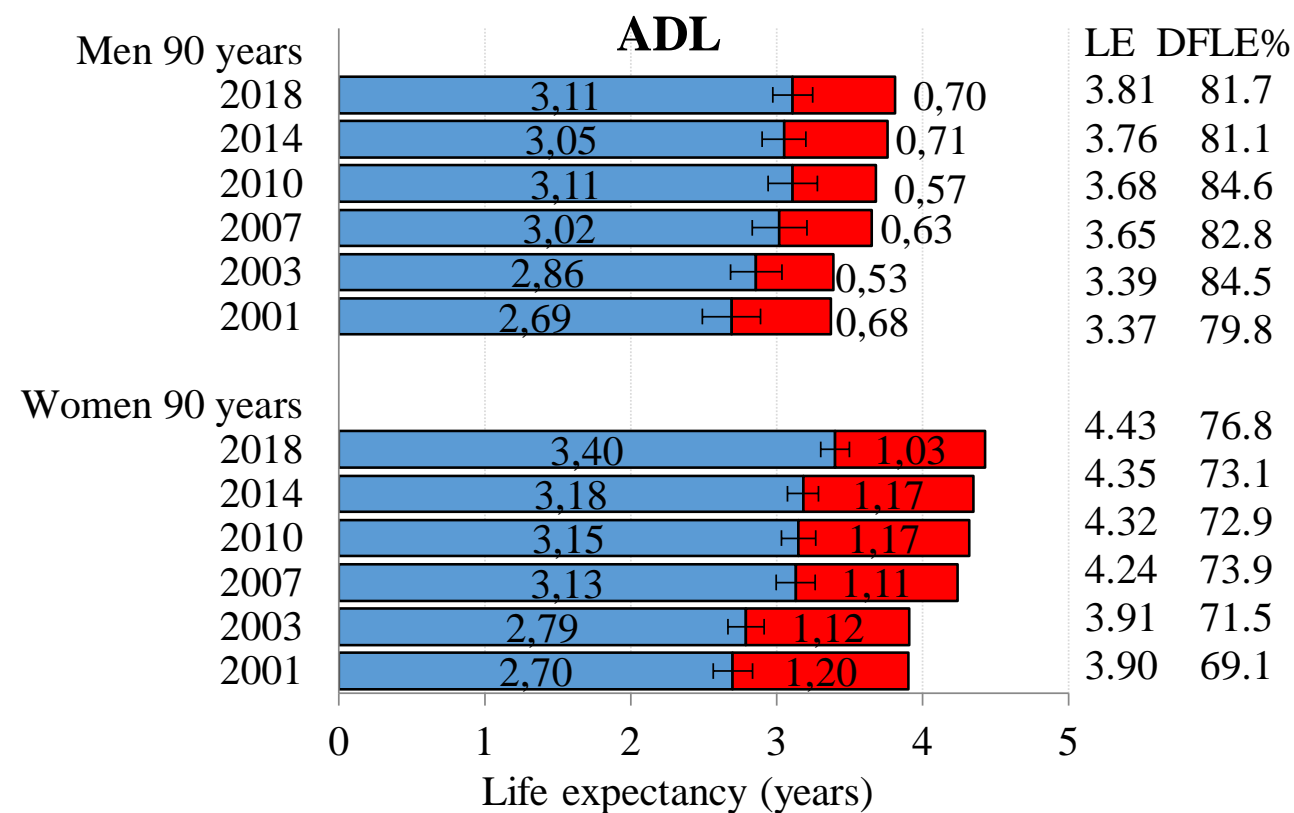

$\square$ Disability-free $\quad \square$ With disability

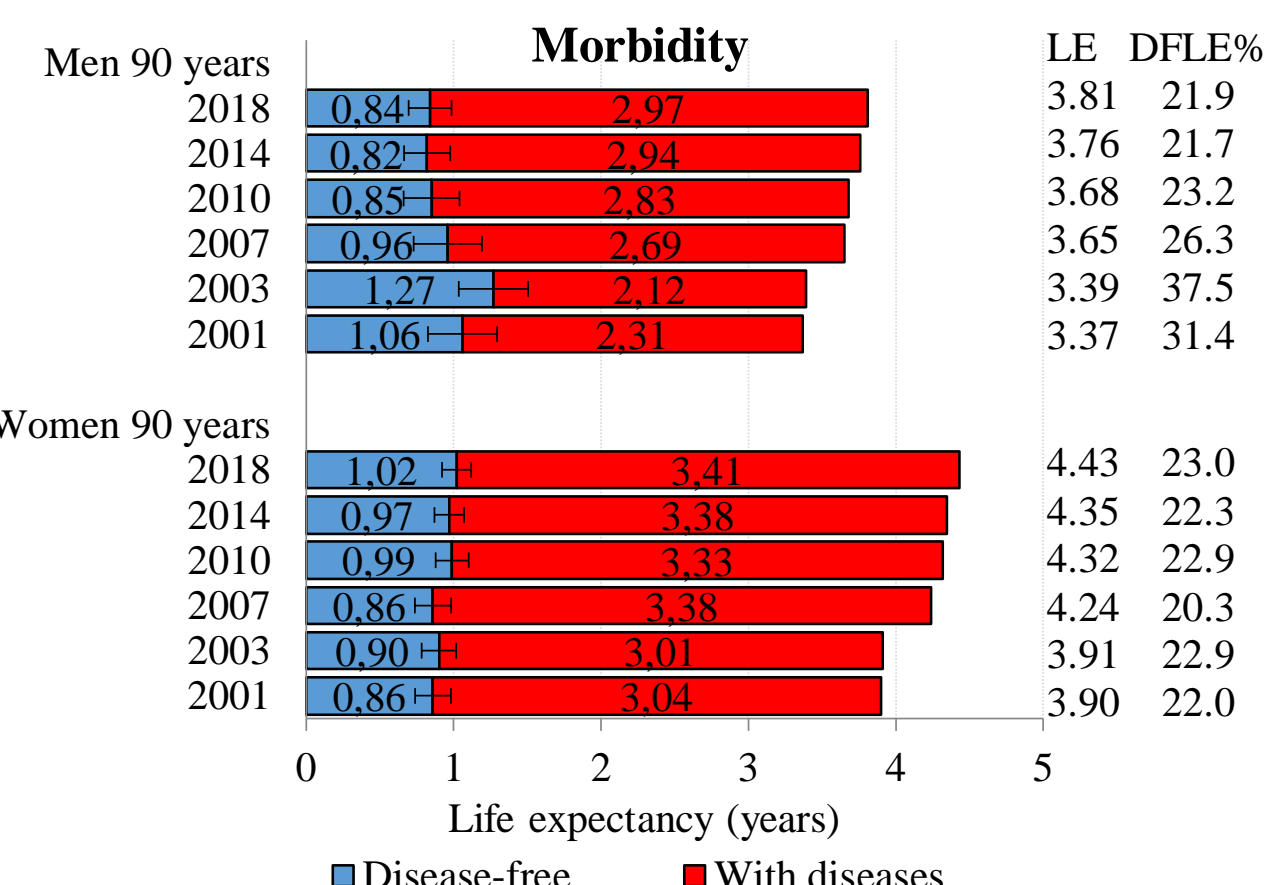

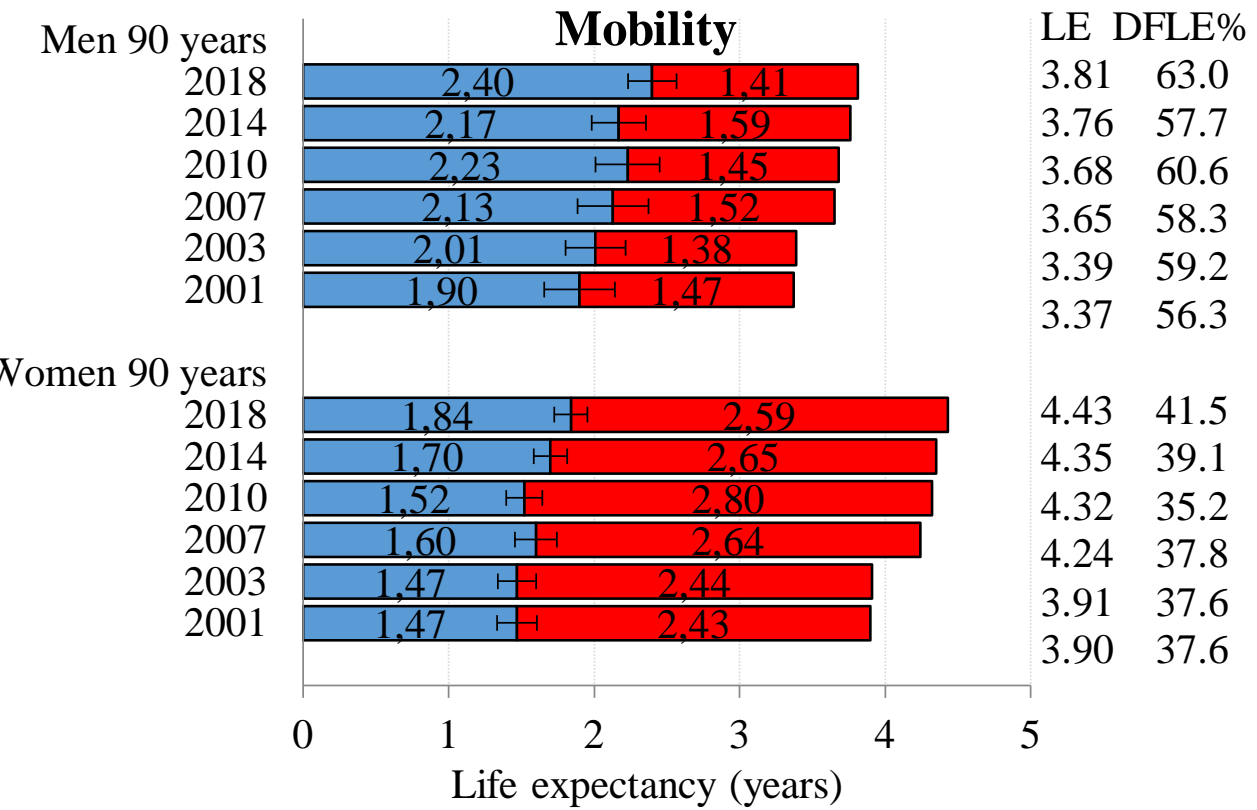

$\square$ Disability-free $\quad \square$ With disability
LE DFLE\%

$3.81 \quad 63.0$

$3.76 \quad 57.7$

$3.37 \quad 56.3$

$4.43 \quad 41.5$

$4.35 \quad 39.1$

$4.32 \quad 35.2$

$4.24 \quad 37.8$

3.9137 .6

5 
Figure 2. Life and health expectancies (in years) at age 90 by sex in the Vitality 90+ Study 2001-2018.

Note. ADL = activity of daily living, LE = life expectancy, DFLE = disability-free life expectancy or disease-free life expectancy. DFLE is calculated as a proportion of total LE. 


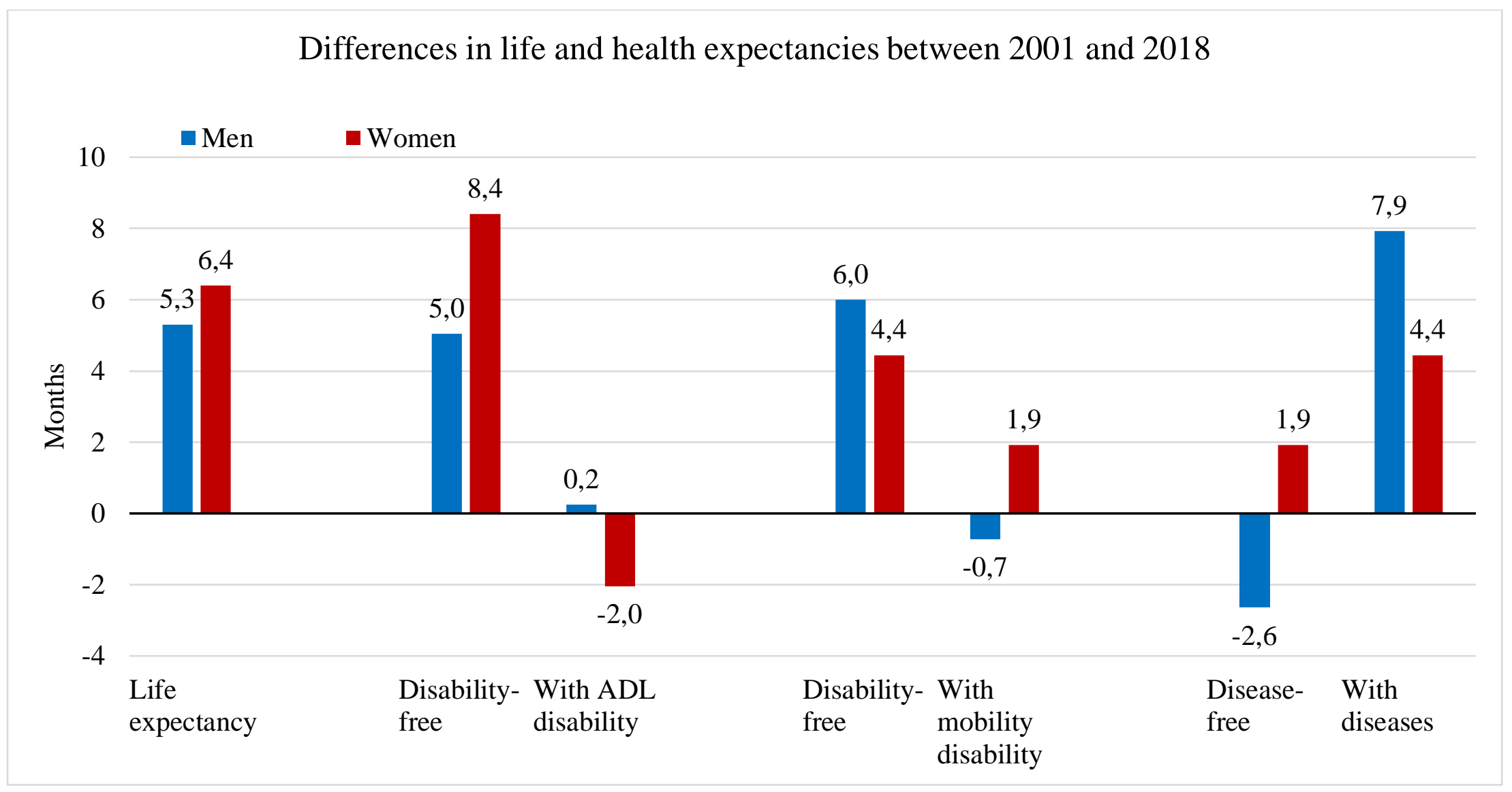

Figure 3. Differences in life and health expectancies (in months) for 90-year-olds by sex in the Vitality 90+ Study between 2001 and 2018.

Note. The reference year (boldface line) is 2001. Health expectancies do not add up to exactly to the increase in life expectancy due to rounding. 


\section{Supplemental material}

eFigure 1. Trends of functioning between 2001 and 2018 by sex in the Vitality 90+ Study. Observed probabilities and age-adjusted fitted trajectories of functioning after generalized estimating equations.

\section{Get in and out of bed}

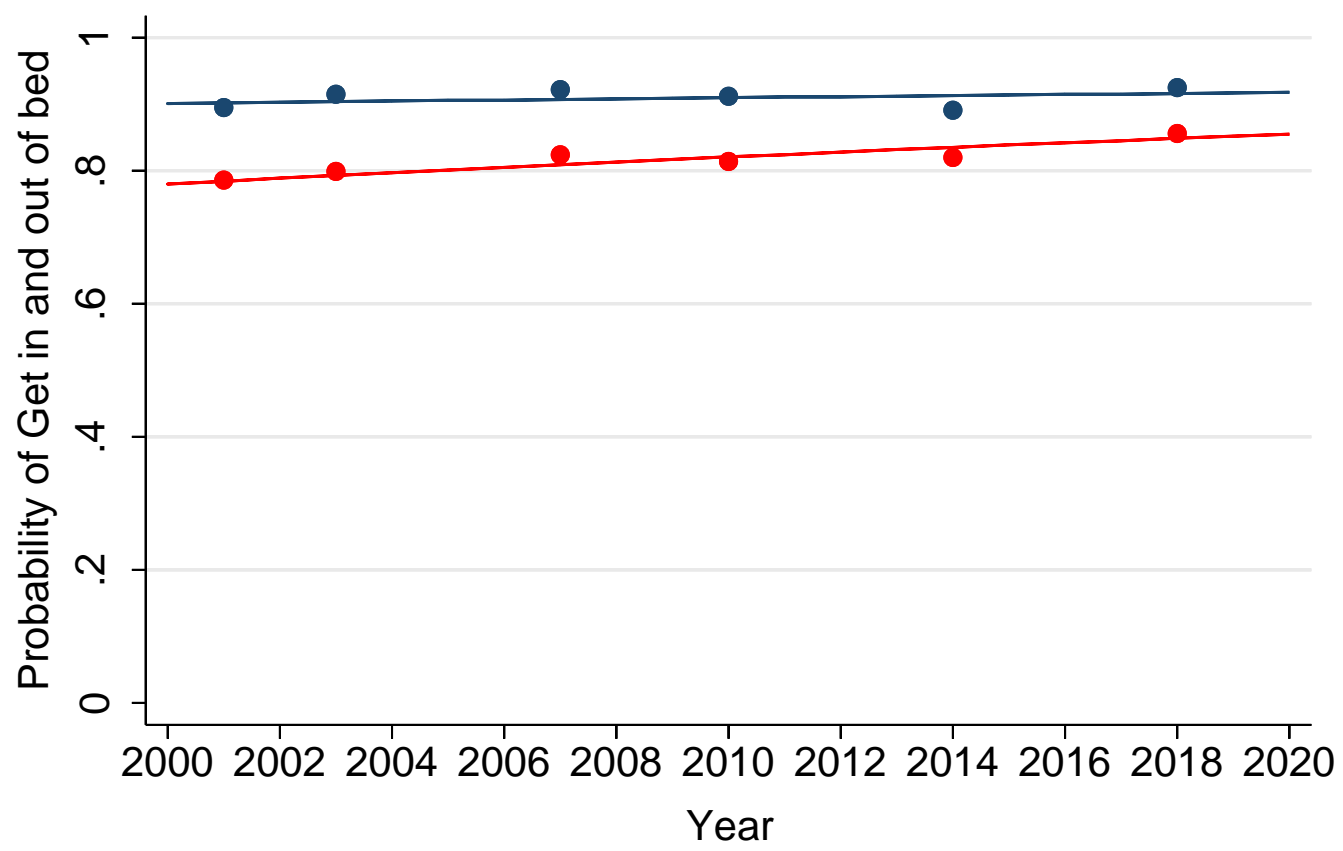
Men (fitted)
- Men (observed)
Women (fitted)
- Women (observed) 


\section{Dress and undress}

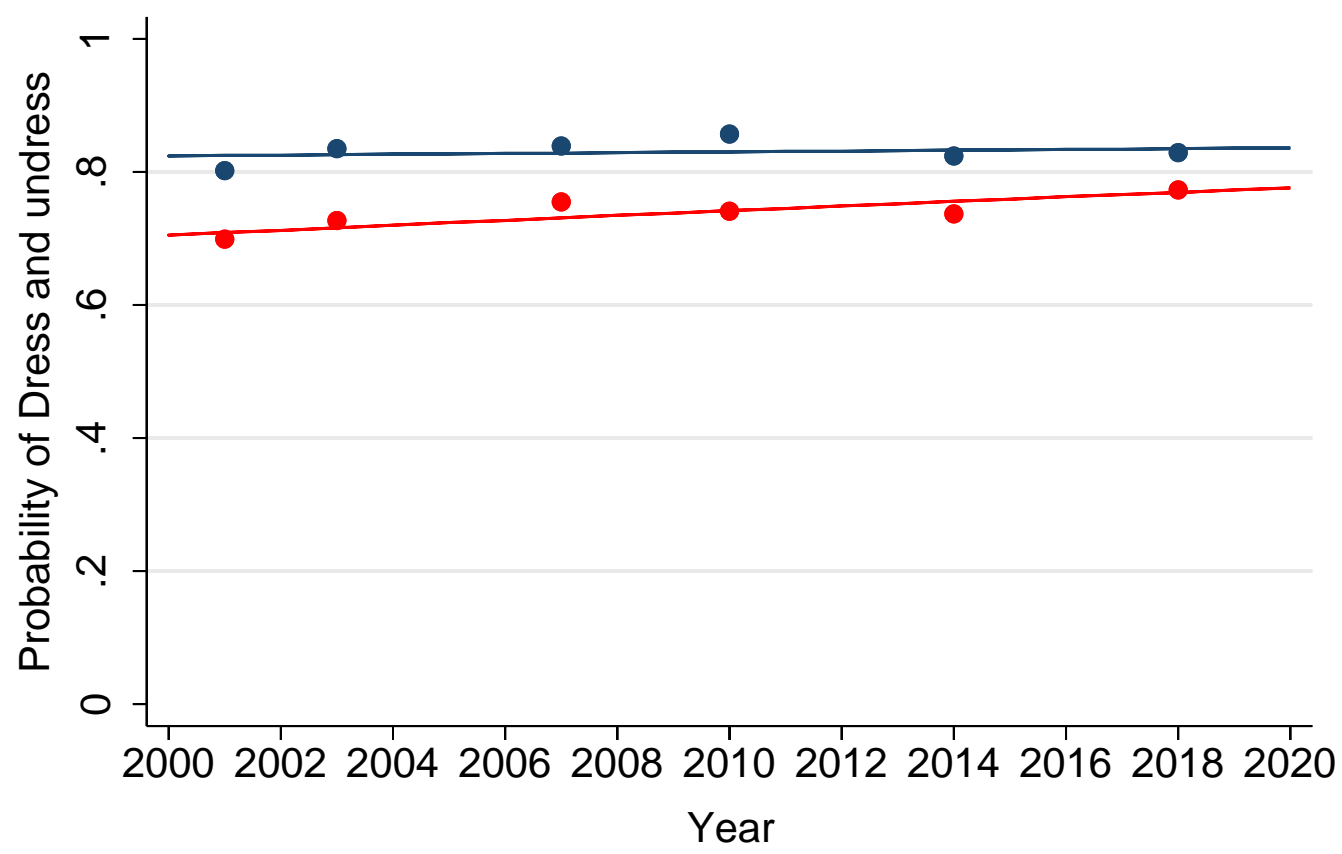

\section{Move indoors}

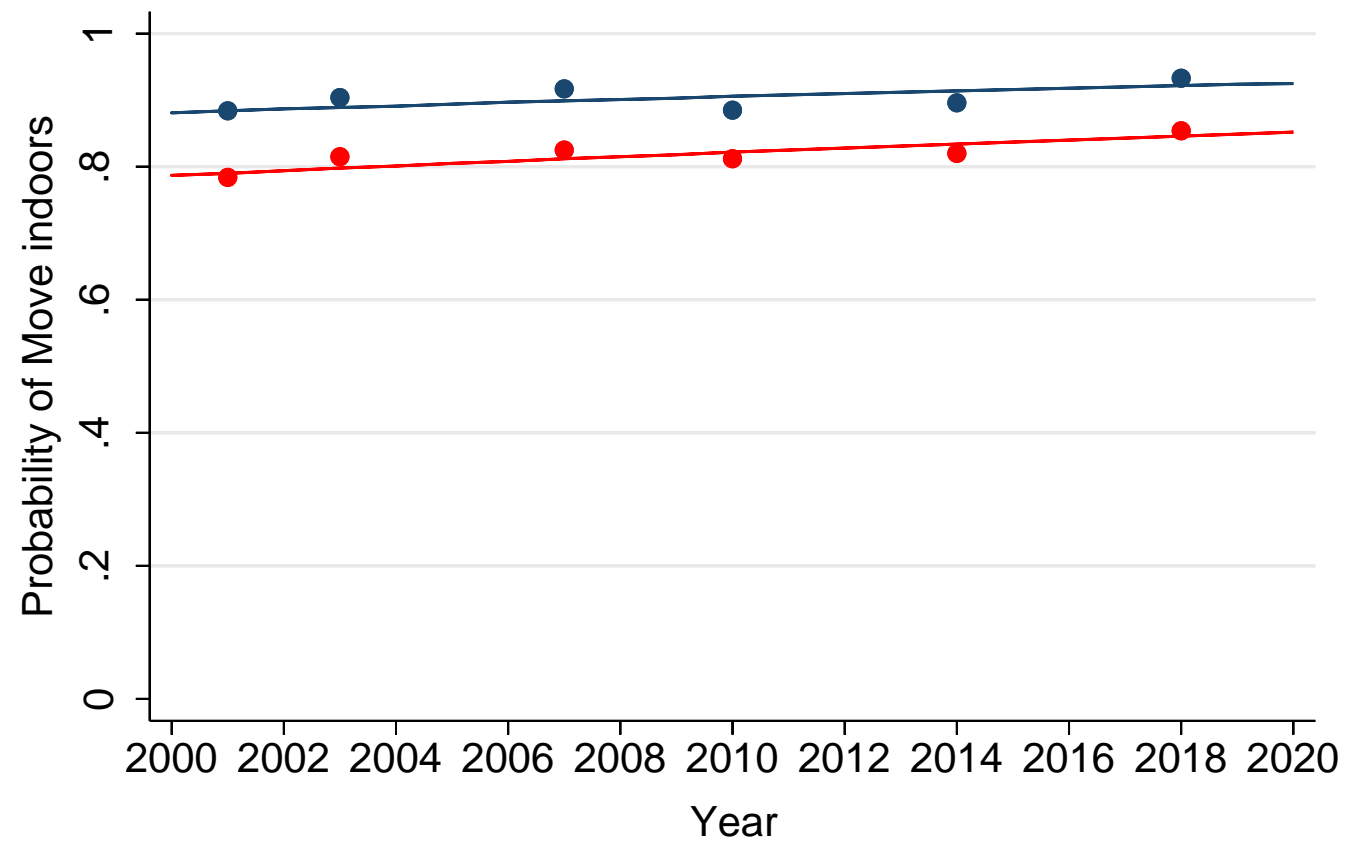
Men (fitted)
- Men (observed)
Women (fitted)
- Women (observed) 


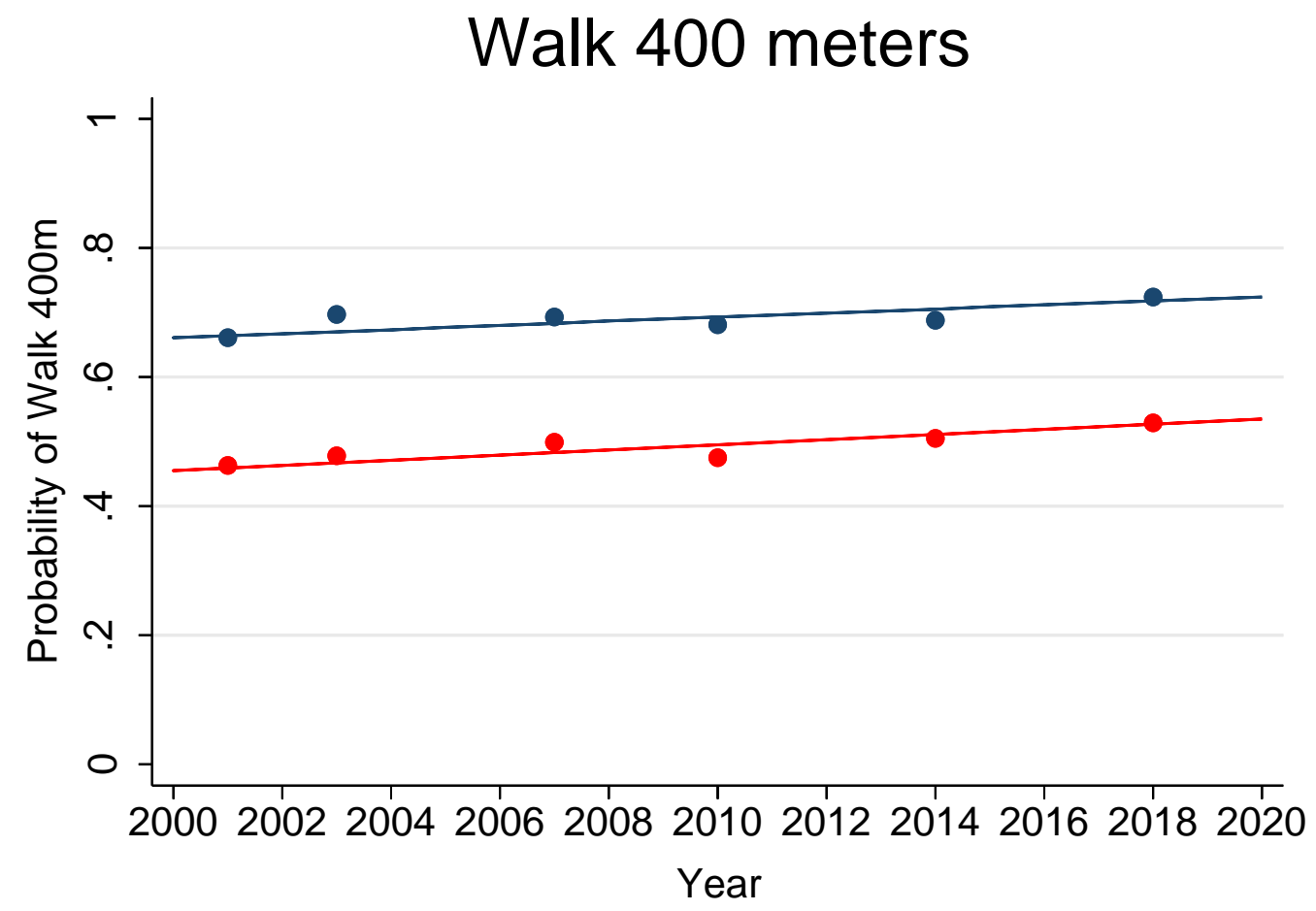

Climb stairs

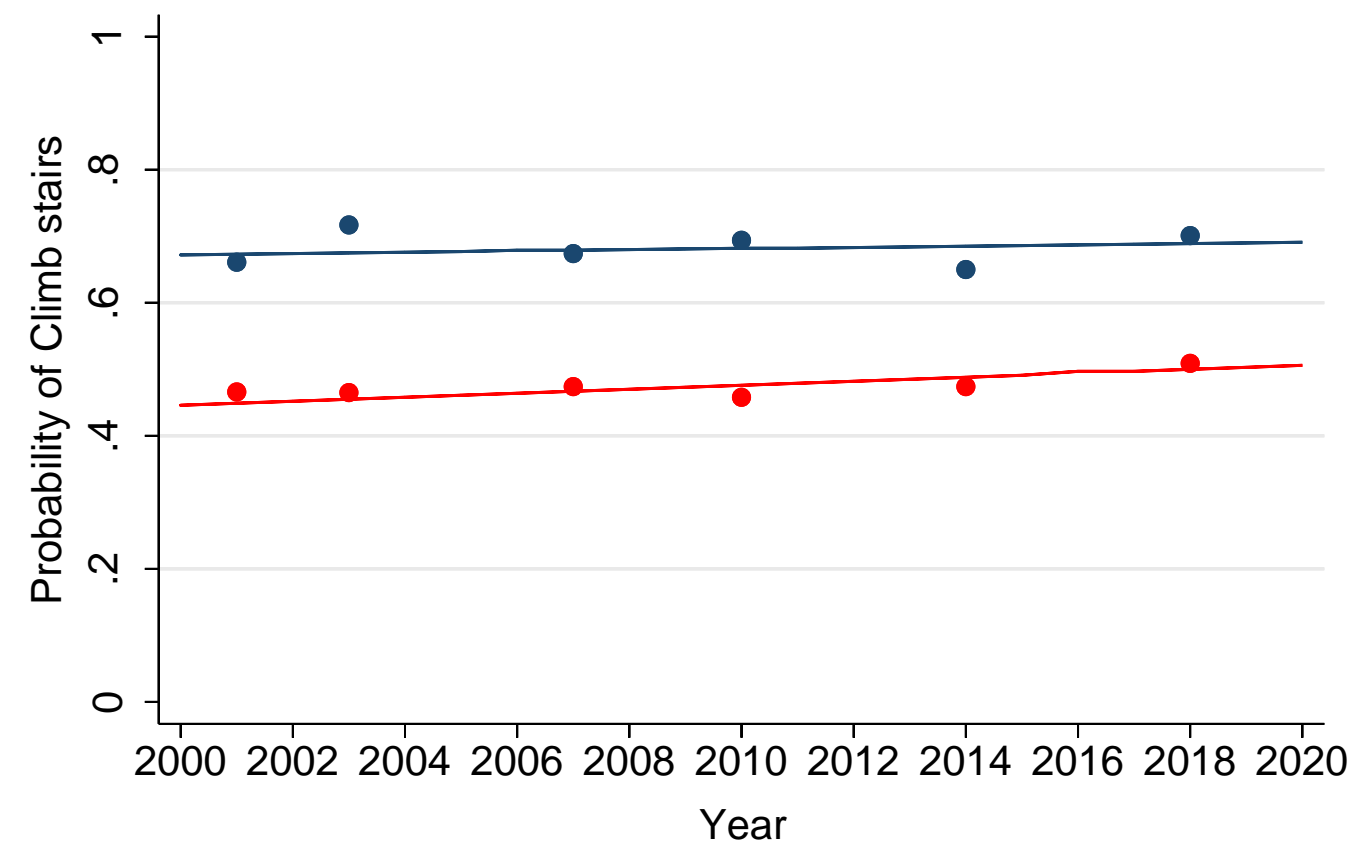
Men (fitted)
- Men (observed)
Women (fitted)
- Women (observed) 
eTable 1. Disability-free life expectancy (DFLE) and disabled life expectancy (DLE) in years and $95 \%$ confidence intervals $(\mathrm{Cl})$ between 2001 and 2018 by sex in the Vitality $90+$ Study.

\begin{tabular}{|c|c|c|c|c|c|c|}
\hline & 2001 & 2003 & 2007 & 2010 & 2014 & 2018 \\
\hline & $\begin{array}{l}\text { DFLE (95\% } \\
\mathrm{Cl})\end{array}$ & $\begin{array}{l}\text { DFLE (95\% } \\
\text { Cl) }\end{array}$ & $\begin{array}{l}\text { DFLE (95\% } \\
\mathrm{Cl})\end{array}$ & $\begin{array}{l}\text { DFLE (95\% } \\
\mathrm{Cl})\end{array}$ & $\begin{array}{l}\text { DFLE }(95 \% \\
\text { Cl) }\end{array}$ & $\begin{array}{l}\text { DFLE }(95 \% \\
\mathrm{Cl})\end{array}$ \\
\hline \multicolumn{7}{|l|}{ ADL } \\
\hline Men & $\begin{array}{l}2.69(2.49- \\
2.88)\end{array}$ & $\begin{array}{l}2.86(2.69- \\
3.03)\end{array}$ & $\begin{array}{l}3.02(2.84- \\
3.21)\end{array}$ & $\begin{array}{l}3.11(2.95- \\
3.28)\end{array}$ & $\begin{array}{l}3.05(2.90- \\
3.20)\end{array}$ & $\begin{array}{l}3.11(2.98- \\
3.25)\end{array}$ \\
\hline Women & $\begin{array}{l}2.70(2.56- \\
2.83)\end{array}$ & $\begin{array}{l}2.79(2.67- \\
2.92)\end{array}$ & $\begin{array}{l}3.13(3.00- \\
3.26)\end{array}$ & $\begin{array}{l}3.15 \text { (3.03- } \\
3.27)\end{array}$ & $\begin{array}{l}3.18(3.08- \\
3.29)\end{array}$ & $\begin{array}{l}3.40(3.30- \\
3.49)\end{array}$ \\
\hline \multicolumn{7}{|l|}{ Mobility } \\
\hline Men & $\begin{array}{l}1.90(1.66- \\
2.14)\end{array}$ & $\begin{array}{l}2.01(1.81- \\
2.21)\end{array}$ & $\begin{array}{l}2.13(1.89- \\
2.37)\end{array}$ & $\begin{array}{l}2.23(2.02- \\
2.45)\end{array}$ & $\begin{array}{l}2.17(1.98- \\
2.35)\end{array}$ & $\begin{array}{l}2.40(2.24- \\
2.57)\end{array}$ \\
\hline Women & $\begin{array}{l}1.47(1.33- \\
1.60)\end{array}$ & $\begin{array}{l}1.47(1.34- \\
1.60)\end{array}$ & $\begin{array}{l}1.60(1.46- \\
1.74)\end{array}$ & $\begin{array}{l}1.52(1.40- \\
1.64)\end{array}$ & $\begin{array}{l}1.70(1.58- \\
1.81)\end{array}$ & $\begin{array}{l}1.84(1.72- \\
1.95)\end{array}$ \\
\hline \multicolumn{7}{|l|}{ Morbidity } \\
\hline Men & $\begin{array}{l}1.06(0.83- \\
1.29)\end{array}$ & $\begin{array}{l}1.27(1.04- \\
1.50)\end{array}$ & $\begin{array}{l}0.96(0.74- \\
1.19)\end{array}$ & $\begin{array}{l}0.85(0.67- \\
1.04)\end{array}$ & $\begin{array}{l}0.82(0.66- \\
0.97)\end{array}$ & $\begin{array}{l}0.84(0.69- \\
0.98)\end{array}$ \\
\hline Women & $\begin{array}{l}0.86(0.74- \\
0.98)\end{array}$ & $\begin{array}{l}0.90(0.78- \\
1.01)\end{array}$ & $\begin{array}{l}0.86(0.74- \\
0.98)\end{array}$ & $\begin{array}{l}0.99(0.88- \\
1.10)\end{array}$ & $\begin{array}{l}0.97(0.87- \\
1.07)\end{array}$ & $\begin{array}{l}1.02(0.92- \\
1.12)\end{array}$ \\
\hline וחת & DLE $(95 \% \mathrm{Cl})$ & DLE $(95 \% \mathrm{Cl})$ & DLE (95\% Cl) & DLE (95\% Cl) & DLE (95\% Cl) & DLE (95\% Cl) \\
\hline Men & $\begin{array}{l}0.71(0.51- \\
0.90)\end{array}$ & $\begin{array}{l}0.53(0.36- \\
0.70)\end{array}$ & $\begin{array}{l}0.68(0.50- \\
0.86)\end{array}$ & $\begin{array}{l}0.64(0.48- \\
0.81)\end{array}$ & $\begin{array}{l}0.71(0.56- \\
0.86)\end{array}$ & $\begin{array}{l}0.70(0.56- \\
0.83)\end{array}$ \\
\hline Women & $\begin{array}{l}1.21(1.07- \\
1.34)\end{array}$ & $\begin{array}{l}1.11(0.99- \\
1.24)\end{array}$ & $\begin{array}{l}1.11(0.98- \\
1.24)\end{array}$ & $\begin{array}{l}1.17(1.05- \\
1.29)\end{array}$ & $\begin{array}{l}1.17(1.06- \\
1.27)\end{array}$ & $\begin{array}{l}1.03(0.94- \\
1.13)\end{array}$ \\
\hline \multicolumn{7}{|l|}{ Mobility } \\
\hline Men & $\begin{array}{l}1.50(1.26- \\
1.74)\end{array}$ & $\begin{array}{l}1.38(1.18- \\
1.58)\end{array}$ & $\begin{array}{l}1.57(1.33- \\
1.81)\end{array}$ & $\begin{array}{l}1.53(1.31- \\
1.74)\end{array}$ & $\begin{array}{l}1.59(1.41- \\
1.77)\end{array}$ & $\begin{array}{l}1.41(1.24- \\
1.57)\end{array}$ \\
\hline Women & $\begin{array}{l}2.44(2.30- \\
2.57)\end{array}$ & $\begin{array}{l}2.44(2.31- \\
2.57)\end{array}$ & $\begin{array}{c}2.64(2.50- \\
2.78)\end{array}$ & $\begin{array}{l}2.80(2.68- \\
2.92)\end{array}$ & $\begin{array}{l}2.65(2.53- \\
2.76)\end{array}$ & $\begin{array}{l}2.59(2.48- \\
2.70)\end{array}$ \\
\hline \multicolumn{7}{|c|}{ Morbidity } \\
\hline Men & $\begin{array}{l}2.34(2.11- \\
2.57)\end{array}$ & $\begin{array}{l}2.12(1.89- \\
2.34)\end{array}$ & $\begin{array}{l}2.74(2.51- \\
2.97)\end{array}$ & $\begin{array}{l}2.91(2.72- \\
3.09)\end{array}$ & $\begin{array}{l}2.94(2.79- \\
3.10)\end{array}$ & $\begin{array}{l}2.97(2.83- \\
3.12)\end{array}$ \\
\hline Women & $\begin{array}{l}3.05(2.93- \\
3.17)\end{array}$ & $\begin{array}{l}3.01(2.90- \\
3.13)\end{array}$ & $\begin{array}{l}3.38(3.26- \\
3.50)\end{array}$ & $\begin{array}{l}3.33(3.22- \\
3.44)\end{array}$ & $\begin{array}{l}3.38(3.28- \\
3.48)\end{array}$ & $\begin{array}{l}3.41 \text { (3.31- } \\
3.51)\end{array}$ \\
\hline
\end{tabular}

Note. Disabled life expectancies are not identical to those presented in Figure 2 due to rounding. 